\title{
Higher Education Institutions without Foreign Language Continuity
}

\author{
Slavica Čepon ${ }^{1}$ \\ ${ }^{1}$ Faculty of Economics, University of Ljubljana, Slovenia \\ Correspondence: Slavica Čepon, Kardeljeva ploscad 17, 1000 Ljubljana, Slovenia. Tel: 38-64-183-7379. E-mail: \\ slavica.cepon@ef.uni-lj.si
}

Received: April 9, 2012 Accepted: May 14, 2012 Online Published: July 2, 2012

doi:10.5539/elt.v5n8p31 URL: http://dx.doi.org/10.5539/elt.v5n8p31

\begin{abstract}
This article attempts to fill a research gap in the literature where there is no research in the available literature on the general foreign language/foreign-language-for-specific-purposes discontinuity at the secondary/tertiary interface. The article reports on the findings of a study that aimed to acquire the opinions of the teachers of foreign languages for specific purposes regarding various approaches to managing a general foreign language/foreign-language-for-specific-purposes transition period. Namely, at some European, including Slovenian, institutions of higher education there is no foreign language instruction for first-year students. As a consequence, discontinuity at this crucial secondary/tertiary interface may give rise to general foreign language attrition - an obstacle to subsequent foreign-language-for-specific-purposes learning in higher education. The results of in-depth interviews with 29 teachers point towards grammar in the second year as a factor interconnecting interrupted general foreign language instruction with foreign languages for specific purposes.
\end{abstract}

Keywords: higher education, foreign language discontinuity, language attrition, foreign languages for specific purposes, explicit instruction, implicit instruction, grammar

\section{Introduction}

At some European and Slovenian institutions of higher education there is no foreign language (FL) instruction at the secondary/tertiary interface. The need for continuous FL instruction is especially dire in environments where an FL is not present naturally (Hansen, 2001; Scarino, 2003; Schmitt, 2010), however, as a rule, gaps occur at the primary/secondary and secondary/tertiary interface in FL instruction (Purvis \& Ranaldo, 2003; Scarino, 2003; Cunningham, 2004; 2010; ECML, 2010). Problematically, it is often assumed that university entrants possess good general knowledge of an FL, usually English, which is then only to be enhanced with communicative language competence and specialized vocabulary within a specific academic, occupational or professional domain (Räisänen \& Fortanet-Gomez, 2008a). Quite often such is not the case, and, worse, one of the most persistent problems in higher education is the gradual attrition of FL competence due to an FL discontinuity (Yoshitomi, 1992; Ecke, 2004) that is manifest most visibly in the form of declining grammatical competence and writing skills (Klapper, 2006; Skela et al., 2009).

Another acute problem in tertiary environments under the Bologna changes are systemic inconsistencies along with the lack of clearly defined FL policy in the common European higher education area (Djurić \& Jurkovič, 2008), the reduction of the actual number of FL hours allotted, and the unsettled status of FL teachers (Steigler-Peters et al., 2003; Jurkovič et al., 2008). The combined result is a deleterious effect on FL instruction.

Though the problem is widespread, the example of Slovenia is instructive. A hefty percentage of tertiary institutions in Slovenia do not offer an FL at all or provide only English instruction (see Djurić et al., 2008; Rižnar, 2010). For one instance, at the Faculty of Economics in Ljubljana (FELU) there is no organized FL instruction for first-year students at all. Language needs analysis of the economics students at FELU suggest that the consequences of the prior incomplete FL acquisition combined with FL discontinuity at the secondary/tertiary interface results in the attrition of the logical structure of general FL knowledge that is considered vital for subsequent foreign-language-for-specific-purposes instruction (FLSP) (Note 1) (Čepon, 2006).

The lack of research in the available literature on the FL discontinuity at the general FL/tertiary FLSP interface motivated this study in an attempt to help fill the gap in the literature. We use in-depth interviews with 29 FLSP teachers to explore FLPS teachers' opinions regarding various means to ameliorate the effects of FL 
discontinuity and smooth the transition to FLSP instruction.

\section{Theoretical Background}

\subsection{Continuity in FL Learning}

Several researchers (see DeKeyser, 2007) have attributed the progress of more advanced FL students to more exposure and interaction in FL or more ingenuity in providing good opportunities for practising all four FL skills. However, intrinsically-motivated individuals, after a long gap, forgot fewer structures, had better recall and less attrition than students that did not (see Hansen, 2001; Ecke, 2004). Contemporary studies of the effects of FL discontinuity illustrate that FL disuse gives rise to FL attrition (Hansen, 2001; Crossling \& Ward, 2002; Schmid et al., 2006; Evans, 2010; Hafizoah \& Fatimah, 2010). Essentially, not using/learning an FL continuously, as might be intuited, necessitates a process of FL retrieval (see Hansen, 2001; Ecke, 2004), and that process is manifest in varying degrees.

Continuity in FL learning arising from increased frequency of use and its input are crucial variables in language attrition models of information (Hansen, 2001; Ecke, 2004). Similarly, the notion of limited input-processing capacity of FL learners is at the foundation of several FL teaching/learning approaches (Pienemann, 2003). The Activation Threshold Hypothesis (ATH) maintains that continuous, frequent FL use and its temporal proximity determine how easily an FL can be accessed (Schmitt, 2010). The same notion underlies Usage-Based Theories that emphasize the positive impact of frequency and repetition on FL learners' cognitive representations (Bybee, 2008). Predictably, a savings paradigm focuses on the advantages of relearning/reintroducing previously learned FL items over new ones (see de Bot et al., 2000; Hansen, 2001); whereas expert literature from the area of FL literacy demonstrates lesser language attrition in more literate individuals (see Hansen \& Reetz-Kurashige, 1999).

\subsection{The Notions of Implicit/Explicit in Grammar Instruction}

The notions of implicit/explicit and incidental/intentional are far from being clearly defined in FL acquisition theory (see Hulstijn, 2001). In language learning the term implicit mostly refers to a brief, incidental instructional attention to linguistic features within a communicatively meaningful context within which the teacher waits for a real-time problem-oriented trigger to appear incidentally (Doughty, 2003), whereas the term explicit encompasses teacher-fronted instruction and raising metalinguistic knowledge. Implicit learning is apparently as effective as a pure focus on linguistic forms (see Norris \& Ortega, 2000).

In the notions of implicit and explicit systems, conscious and subconscious processes are interwoven and their interface is transient: it happens during conscious processing and leaves a long-lasting impression upon implicit cognition (N. Ellis, 2005). Also a connection between conscious and subconscious learning has yet not been definitively established, but following are two attempts. The first explains the sequential motives of learning as: novice + externally scaffolded attention $\rightarrow$ internally motivated attention $\rightarrow$ explicit learning $\rightarrow$ explicit memory $\rightarrow$ implicit learning $\rightarrow$ implicit memory, automatization and abstraction $=$ expert (N. Ellis, 2005). The second attempt presents the three stages of the transition from consciously held, explicit, declarative knowledge of grammar, to not consciously held, procedural grammar, retrieved from memory: a cognitive stage with explicit rules, an associative stage that requires consistent repetition of rules, and finally, a highly-coordinated, implicit, autonomous stage (Segalowitz, 2003).

The term grammar acquisition seems to encompass both an application of consciously held, explicit rules as well as not consciously held, memorized exemplar-based processes in FL learners (see DeKeyser, 2001). According to experts, grammar still holds a central position in language teaching (R. Ellis, 2006) and may foster more subconscious FL learning and improve learners' interlanguage (Nassaji, 2000; Norris \& Ortega, 2000; Doughty, 2003; Robinson, 2003; Lyster, 2004a; Lyster, 2004b; R. Ellis, 2006; Klapper, 2006; Dörnyei, 2009). It appears to be a useful pedagogical tool that may reverse FL attrition (Tudor, 1996), and is even a motivational, rather than anxiety-contributing factor (Turula, 2002; Klapper, 2006). Since the communicative approach as the currently established FL teaching pedagogy does not provide any answers regarding the attainment of communicative competence, some researchers have established that grammatical competence, interwoven with meaning, social function and discourse, may be, along with sociolinguistic and strategic competences, crucial for mastering communicative competence (Celce-Murcia, 2001; Cook, 2001; Larsen-Freeman, 2001).

Implicit grammar instruction is therefore attention-oriented and promotes intuitive awareness of linguistic norms and not declarative knowledge of grammar (Doughty, 2001; 2003; R. Ellis, 2005; Bybee, 2008; Dörnyei, 2009). Paradoxically, one of the issues that experts point out is that implicit learning is not just fully unconscious (Dörnyei, 2009). For effective implicit learning to take place, whether intentionally or incidentally, learners need 
to pay conscious attention to morphological, orthographic, prosodic, semantic and pragmatic features of the target input (Norris \& Ortega, 2000; Doughty, 2003; Robinson, 2003; Lightbown \& Spada, 2006; Bybee, 2008; Dörnyei, 2009).

Consequently, the body of evidence demonstrating the overall effectiveness of corrective feedback and stimulated recall in explicit FL instruction (de Bot et al., 2005; Lightbown \& Spada, 2006) has led some theorists to doubt that mere unintentional exposure to an FL during communicative focus in implicit learning could improve FL learners' interlanguage. (Norris \& Ortega, 2000; Lyster, 2004a; Lyster, 2004b). On the condition that learners have reached the requisite cognitive developmental stage, explicit instruction appears to enhance subsequent noticing and monitoring of the gap between the correct FL input and learners' incorrect interlanguage, and enable FL learners to internalize grammatical rules (Norris \& Ortega 2000; N. Ellis, 2005; R. Ellis, 2005; Klapper, 2006).

Within the notion of grammar acquisition, the present study is concerned with grammar revision and grammar instruction (explicit and/or implicit) in FLSP contexts (Hayland, 2002) that encompass all core grammatical areas and language forms typical of a general FL, yet adapted for the communication needs typical of specific discourses, genres and interactions. Essentially, if in general FL there should be more emphasis on the selection of a 'right' methodological approach to grammar teaching (see Larsen-Freeman, 2001), the FLSP context would require more emphasis on finding the right measure of grammar for the target group of learners.

\section{Method}

\subsection{Research Design}

On the basis of in-depth interviews we explored FLSP teachers' opinions on managing FL discontinuity at the general FL/tertiary FLSP period. In-depth interviews enable a researcher to go deep, to open novel problem dimensions and provide a clear, accurate and inclusive argument based on a personal experience (Denzlin $\&$ Lincoln, 2000). Thus, the in-depth interviews enabled us to compare a variety of standpoints that the respondents provided regarding the FL discontinuity at the general FL/tertiary FLSP period.

The main thematic areas in the interviews were (1) the effects of secondary/tertiary FL discontinuity on subsequent FLSP instruction; (2) reasons for maintaining FL continuity from secondary to higher education settings, and (3) alleviating the consequences of FL discontinuity in higher education settings. We conducted the interviews in winter 2011/2012 in places according to the interviewees' choice, most often at their workplace. The interviews took approximately half an hour. They were transcribed and analyzed by author. Since with in-depth interviews there must be an inherent belief in the trustworthiness of the respondents' accounts (Denzlin \& Lincoln, 2000), we decided to illustrate the results with several quotations from the informants. They were translated into English in such a way as to retain the original idea expressed by the interviewees while retaining the conversational style - in other words, as far as possible the translations reflect both style and content accurately. At the same time, the quotations serve the purpose of avoiding a danger of interpreting the data through the author's own perceptions or making unsupported claims, all with a view to increasing the credibility of the interpretations.

\subsection{Sampling Procedures}

To collect a representative sample of interviewees we invited all 71 FLSP teachers from all four Slovenian universities to attend the interview and 29 teachers responded. They all have prolonged engagement in the field and plenty of FL teaching experience, therefore they provided a rich, experiential account of various perspectives regarding this crucial transition period (see Denzlin \& Lincoln, 2000).

\subsection{Participant Characteristics}

We interviewd the teachers of English (18), German (4), Italian (2) and French for specific purposes (1) and teachers of different combinations of FLSPs, such as English and German (2), English and Italian (1) and English and French for specific purposes (1). 18 teachers teach FLSPs at faculties with FL continuity and 11 teach FLSP at faculties without FL continuity. Among them were 27 females and 2 males, and they were between 30 and 58 years old.

\section{Results}

The results will be presented grouped around the following issues: (1) the consequences of the FL discontinuity period at the secondary/tertiary interface; (2) reasons for maintaining FL continuity at the secondary/tertiary interface, and (3) alleviating the impact of FL discontinuity in higher education settings. The analysis of the interviewees' replies did not show that the fact whether the interviewees teach at the faculties with or without FL 
continuity influenced their choices since one third of the teachers - almost all from the faculties with continuity in FL instruction, rate the secondary/tertiary FL discontinuity as extremely important. Equally, there are no differences in their replies that could be attributed to their age, gender, the amount of experience that they have or the language that they teach. However, one FLSP teacher from a faculty without FL continuity consistently down-palyed the significance and the impact of FL discontinuity.

\subsection{The Effects of the FL Discontinuity at the Secondary/Tertiary Interface}

The fact that there is no FL discontinuity at some faculties at the secondary/tertiary interface is estimated by the informants as follows: half of the informants rate it as harmful and with influence on subsequent FL instruction and the other half as either deleterious or as exerting no influence on subsequent FL instruction (among them one teacher from the faculty without FL continuity). In the words of Nina (English and Italian for Specific Purposes; faculty with continuity), 'Every year of FL discontinuity is a huge loss, the students lose their self-confidence, the grammar vanishes, and instead of tackling an FLSP in a good FL condition, teachers first have to revise general language and grammar...continuity is absolutely paramount'. Metka (English for Specific Purposes (ESP); faculty without continuity) remarks that 'especially the students who are thinking of upgrading their bachelor's studies at the MA and Phd levels would appreciate more continuity in FL instruction, an FLSP for at least two years (four semesters) at the faculty, but with the start of classes in the first year to avoid FL attrition. Unfortunately, these needs apparently cannot be met due to FL discontinuity in the first year and too few hours of an FL at the faculty. Mastering an FLSP at an adequate level requires more hours than allotted currently at the faculty.'

Not all informants are entirely convinced that FL discontinuity exerts a major impact on the students' already diminishing FL communicative competence. Almost two thirds of the informants are convinced that the students' FL oral proficiency practice is largely neglected already in the secondary school. A typical statement is from Polona (German for Specific Purposes; faculty without continuity): 'In my opinion, less proficient FL students who were not able to communicate and speak well in a FL in the secondary school are not affected by the FL discontinuity as much as the more advanced FL students. They simply don't have much to lose.' Quite a few informants also think that the FL communicative competence of Slovenian secondary school graduates is rather underdeveloped since in secondary schools there may still be too much emphasis on grammar, mainly as a consequence of the washback effect of the Slovenian 'matura' exam requirements (Zavašnik \& Pižorn, 2006).

Nevertheless, regardless of how the interviewees rate the impact of FL discontinuity on the forthcoming FLSP instruction they all admit that FL continuity from pre-tertiary to tertiary FL instruction is 'desirable, if not downright necessary, and above all, would be fair to language students who are expected to compete against each other in modern labour markets', to use the words of Polona (German for specific purposes; faculty without continuity). Most of the FLSP teachers claim that especially for non-native speakers such FL continuity is absolutely vital, mainly due to their still incomplete FL acquisition from pre-tertiary periods.

\subsection{Reasons for Maintaining FL Continuity from Secondary to Higher Education Settings}

Two main reasons that maintaining FL continuity at the secondary/tertiary interface is rated as paramount are, firstly, the nature of the connection between a general FL and subsequent FLSP instruction, and secondly, the disappearance of a general FL; that is, general FL attrition.

All interviewees emphasize an inseparable connection between a general FL and an FLSP, therefore the intact general FL as the basis for building FLSP knowledge is deemed indispensable by all of them. A typical statement was from Alenka (business English; faculty without continuity): 'There is no FLSP instruction without a general FL. A good example is a business lunch where talking shop exclusively is out of the question, and small talk is absolutely vital'. Marijana (ESP; faculty with continuity) reminds us that 'Learning a FLSP requires a long time and is best done via a comparison with a general FL'.

Regarding the second reason for retaining FL continuity, the deleterious effects of general FL attrition are among the most commonly stated replies. According to almost one third of the teachers, practically all from the faculties with FL continuity, general FL attrition results in dire consequences that impact subsequent FL instruction in a negative way. Additionally, two thirds state that the consequences are noticeable, but manageable. Only the same teacher from the faculty with FL continuity is again of the opinion that there are no consequences whatsoever. Based on the findings, it is also possible to conclude that the incidence of noticing general FL attrition in their students' interlanguage is high: very few informants, among them two from the faculties without FL continuity, are faced with general FL attrition 'quite often' and more than one half of all interviewees 'often' notice general FL attrition - among them eleven teachers from the faculties with FL continuity. Slightly fewer than one third seem to encounter it rarely. 
Although acknowledging that not all FL students are equally susceptible to its effects, most interviewees state that the worst consequence of general FL attrition for most students is the disappearance of the logical structure of a general FL. The effects of general FL attrition appear to be particularly detrimental to non-native speakers, mainly due to incomplete FL acquisition from pre-tertiary periods. Alenka's standpoint (business English; faculty without continuity) is that 'Essentially, an FLSP appears to be too difficult for the students who lack the knowledge of the basics of their future profession. If the attrition of a general FL has set in, the whole situation is further complicated. A general FL is of lesser importance at the faculty, but the revision of some general FL topics that the students could be familiar with might help them towards a gradual introduction of FLSP vocabulary'.

\subsection{Alleviating the Impact of FL Discontinuity in Higher Education Settings}

FLSP teachers are quite optimistic regarding the possibilities of mitigating the negative impacts of secondary/tertiary FL discontinuity. Following are some propositions that they have put forward: (1) solving the problem institutionally; (2) more FLSP hours; (3) providing an FLSP course as an elective subject in the first year; (4) organizing FL refresher courses, (5) posting a compilation of FL tests with controlled practice keys on the intranet; (6) introducing first-year students to the complementary methods of learning/revising an FL (e.g., Auralog); (7) enabling first-year students to attend lectures for other subjects in an FL; (8) having subject-area specialists assign first-year students expert literature in an FL; (9) encouraging liaisons between FL teachers and other subject-area specialists as domain experts in their fields of specialization in the first year; (10) encouraging Slovenian first-year students to socialize and study with foreign-exchange students; (11) advising first-year students to read and speak more in an FL, not just browse on the internet; (12) pointing out to the first-year students as laymen in the area of FL instruction that passive FL reception that they resort to during FL discontinuity is not a viable replacement for productive FL learning; (13) emphasizing the necessity of actively seeking out opportunities to retain, revise and improve an FL in a non-native speaking language environment; and finally, (14) pointing out to the first-year students the prospective negative effects of FL discontinuity and FL attrition as a consequence of incomplete acquisition.

This list aside, when thinking of the pedagogical means that could be utilized with a view to alleviating the impacts of the FL discontinuity, the teachers' propositions were varied. Therefore, the results will be presented according to FLSP teachers' suggestions for offsetting the consequences of FL discontinuity in higher education settings: (1) emphasis on all FL abilities; (2) emphasis on selected FL abilities; (3) emphasis on FL lexis; (4) emphasis on grammar.

Almost all FLSP teachers are of the opinion that it should be possible to mitigate the harmful effects of FL discontinuity by placing various levels of emphasis on different components of FL communicative competence and FL abilities. FL communicative competence, the ultimate goal of FL instruction (see Skela, 2011), is perceived as paramount by all informants; therefore almost all of them reason that it must come to the forefront in higher education. In the words of Alenka (business English; faculty without continuity), 'Communicative competence is the most important for the students, despite the mistakes or difficulties in choosing the words. Even with grammatical mistakes oral communication is still possible on the basis of being able to use some FL words.' Nonetheless, the informants are fully aware that the communicative approach does not offer any specific guaranteed answers or methods regarding the achievement of FL communicative competence, especially not when a period of attrition has occurred (Skela, 2011).

Consequently, their replies differ when it comes to methods of teaching FL communicative competence and what emphasis to place on various components of FL communicative competence and FL abilities to offset the ill-effects of FL discontinuity.

\subsubsection{Emphasis on All FL Abilities}

Almost all teachers appear to be convinced that FL abilities are not affected equally by FL discontinuity. Quite a few believe that estimating which FL ability may be deteriorating more rapidly is problematic since they are not familiar with the state of FL students' knowledge upon entry. Most teachers seem to think that the productive FL abilities of speaking and writing are the most affected; just one informant mentions a combination of writing and partly reading skills and another one speaking and listening skills.

Regarding the effects of FL discontinuity on the loss of FL writing ability, none of the teachers disputed the importance of the phenomenon by claiming it was negligible. On the contrary, two thirds reiterate the view that the loss of the ability to write in an FL is harmful, whereas the remaining one third see its consequences as dire or quite important, yet not influencing subsequent FL instruction. The following claim from Metka (ESP; faculty without continuity) is a typical statement: 'FL discontinuity is the single biggest problem for mastering FL 
writing ability. Another acute problem is the small number of FL hours.'

Despite the informants being seemingly undecided regarding how much practice and for what FL abilities they should provide in the second year to minimize the ill-effects of FL discontinuity, one half of the informants, the so-called proponents of all FL abilities, voice the opinion that none of the FL abilities should be neglected. A typical statement is from Zorka (ESP; faculty without continuity): 'Only work on all four FL abilities will produce a competent FL speaker...Although it seems that their receptive abilities are good enough for FLSP, we teachers should not rely on the students' self-initiated reading and listening. Even if they do read and listen, it is probably not going to be reading and listening from an FLSP field. That's basically our duty, regardless of how many hours we have.'

Among the reasons for being in favour of all FL abilities this particular group of informants mention the fact that the range and variety of professional positions open to FLSP graduates from various faculties around Slovenia is practically indefinable. It is therefore impossible for FLSP teachers to operationally define future work-oriented FL skills for different job tasks, so no target discourse samples in the form of specific work-related learning materials can be used for FL instruction (Hyland, 2002). According to Matjaž (business English; faculty without continuity), 'In reality, most faculty graduates will have to re-learn the typical way of communicating in a specific target situation in an FL in their newly found jobs, regardless of the content of the FLSP classes offered at the faculties.'

\subsubsection{Emphasis on Selected FL Abilities}

On the other hand, the other half of the interviewees - the 'opponents' of a balance of all FL skills, hold the view that in an FLSP classroom these should not be dealt with at all costs. For instance, in the words of Sabina (English and German for Specific Purposes; faculty with continuity), the choice for teachers should 'really be based on the future profession and job tasks in the sense that the technicians will need reading more, while negotiators will speak more in an FL. However, this is difficult to know. For example, writing skill has traditionally been neglected in FL classrooms, and I don't see why FLSP teachers should make more time to practise it again at the faculty. Common sense is that the more variety regarding FL skills, the better, but in reality I can't afford that'.

Only three teachers would focus on specific FL skills depending on the language needs of the target group and one FLSP teacher from a faculty without continuity prefers to work only on productive FL skills. As Violeta (ESP; faculty with /without continuity) puts it: 'Not everybody has the same language needs. In our faculty, we cover the requirements of the international convention STCW, so the emphasis is on FL vocabulary and spoken communication, whereas with the students of traffic technology we cover all four FL skills.'

\subsubsection{Emphasis on General FL Lexis}

Developing FLSP lexis is an indispensable part of building FLSP competence to almost all interviewees. According to Nives (Italian for Specific Purposes; faculty without continuity), 'You can make grammatical mistakes and still communicate on a basic level, but if you lack the right words for your line of work, you can't communicate at all. In FLSP, vocabulary is the most important, followed by grammar and practising FL oral proficiency...The students absolutely need to be able to communicate in an FL more or less successfully, and FL lexis is the means to get there.' A typical belief held by one third of informants, that a difficult recall of general FL lexis caused by FL discontinuity may severely impact FLSP instruction, is expressed by Vesna (ESP; faculty with continuity): 'I am sure FL discontinuity will result in a huge loss of FL knowledge from the secondary school. Here I am thinking of general FL lexis that may be used for professional purposes; e.g., words such as length, depth, accuracy, etc. If FL continuity was provided, this vocabulary would not have got lost.' The following citation from Dubravka (ESP; faculty with continuity) reinforces the importance of this fact: 'Business English is intertwined with general English vocabulary, so I don't think I can teach just business English lexis. The students do need to retain a solid basis of general FL vocabulary.'

Nonetheless, regardless of the importance attributed to FLSP lexis, placing emphasis on this sub-area of linguistic competence cannot be utilized to alleviate the effects of FL discontinuity, at least not at the beginning of FLSP instruction in the second year. Namely, the lack of the specialized FLSP lexis of the carrier content in both the students' mother tongue and an FL may be so severe that it practically renders the use of FLSP lexis unattainable. According to the interviewees, even students who have managed to retain adequate FL communicative competence in higher education settings will find themselves at the root of the FLSP conflict between a FL as a real content and discipline-specific carrier content. Maja (ESP; faculty with continuity) claims that 'the students' communicative competence is already rather dubious on enrolment, and, secondly, FLSP learners encounter such new, unfamiliar FL situations in business contexts that even advanced students are at a 
loss for words. What helps them is the fact that they are either fast learners or more motivated to acquire FLSP lexis, which of course helps a bit with communicative competence, but is not all. FLSP contexts are completely different from general FL contexts in secondary schools or when they're browsing on the internet, and the students are completely unaware of that.'

To sum up with the words of Nina (ESP; faculty with continuity), 'FL lexis is possible to improve only by regular use, reading, speaking, performing... If general FL lexis is vanishing due to FL discontinuity, the upgrade with FLSP lexis could be more exacting and less efficient.'

\subsubsection{Emphasis on Grammar}

The results indicate that with a view to eliminating the consequences of FL attrition the interviewees may apply grammar revision or grammar instruction, and, in case they opt for grammar instruction, they may employ explicit or implicit approaches to grammar instruction. The two opposing standpoints between grammar revision and grammar instruction are distributed almost equally among the informants - half are in favour of revision and half in favour of instruction. The factors that they consider when deciding on the amount of each instructional approach do not appear to be based directly on whether the students did or did not encounter the (dis)continuity in FL instruction, but indirectly on: (1) varying levels of the students' general FL knowledge; (2) varying levels of grammar attrition at the start of FLSP instruction; (3) the prospective communication requirements of the students' future profession; (4) the allotted time for an FLSP course; (5) the fact that there could have been too much grammar emphasis in the secondary school; (6) the fact that the students are more cognitively mature at the time of FLSP study.

The dilemma for FLSP teachers appears to be rooted in the following decision: which of the two instructional approaches is more effective when it comes to alleviating the consequences of FL discontinuity? However, it appears that the issue is not finding a clear-cut line between implicit and explicit grammar instruction, rather their combination for FLSP purposes. Based on the results, the views of the informants are divided between explicit and implicit instructional approaches, though always within an FLSP context. About one third of informants argue that deliberate teacher-fronted discussion of grammatical forms in isolation in an FLSP context may be useful to combat FL discontinuity, a view that echoes some experts' opinions (see Norris \& Ortega, 2000; Lyster, 2004a; Lyster, 2004b). The following statement from Sara (German for Specific Purposes; faculty with continuity) summarizes their point of view: 'If we could afford it, then explicit grammar instruction would be welcome. It would alleviate subsequent FLSP study and probably level off serious differences in the students' knowledge that we encounter. The most logical thing to do would be to employ explicit grammar instruction for poorer FL students only; however, this may be too difficult in a FL classroom at the tertiary level'.

The underlying logic of the proponents of explicit grammar instruction seems to be that FLSP students in higher education should be cognitively mature enough for the development of their metacognitive skills that, subsequently, may help the students to internalize grammatical rules and improve their interlanguage. However, in practice, the effects of FL discontinuity may be too severe to allow for any serious reliance on the students' interlanguage.

Although quite a few informants state that they are in fact already employing both instructional types, about two thirds prefer incidental, implicit treatment of grammatical problems incorporated in meaning: according to Mirella (Italian for Specific Purposes; faculty with continuity), 'If implicit grammar instruction is the one that seems to foster intuitive awareness of grammar, not conscious awareness of linguistic rules, then this is a way to tackle grammar at the tertiary level.' Mateja (ESP, faculty without continuity), claims that 'more proficient FLSP students might even be put off by explicit grammar, so an implicit approach seems more appropriate for them. However, a recurrent grammatical problem may still be tackled explicitly'.

The findings of the study indicate that implicit grammar instruction is employed as an instructional approach aimed at redirecting the students' attention towards the correct input during FL input processing. A guiding principle for the FLSP teachers appears to be catching the students' attention in the midst of a grammatical problem as well as raising their awareness of the correct FL input. Among a variety of ways of bringing the students' attention to grammar without giving explicit explanation the informants mention the following as the most commonly used: a) subtly slipping grammatical discussion in as support for other activities; b) highlighting features of the input; c) paraphrasing the students' sentence to highlight the mistake and d) the use of implicit unobtrusive exchanges between students and teacher instead of a direct correction; i.e., recasting (Note 2). Consequently, the students become sensitized to monitoring the input, comparing it with their interlanguage, and improving their output and intake without any metalinguistic focus.

Implicit grammar is thus not to be understood as simply unintentional exposure to a teacher's pedagogical 
interventions within a communicative focus, but as an attempt by FLSP teachers to rely on the learners' noticing varying aspects of the correct FL input. The teachers state that the more a learner pays attention to FL input, whether intentionally or incidentally, the more likely it is that the new information will be retained.

The proponents of implicit grammar instruction give the following reasons for not employing an explicit grammar approach: (1) too few allotted hours of FL instruction; (2) the target group of FLSP students clearly differentiate between real and carrier content in FLSP instruction and demand as little metalinguistic awareness as possible; (3) some FLSP students seem to be oversaturated with grammar from the secondary school; (4) as a consequence of incomplete acquisition and FL discontinuity period, metalinguistic awareness of specific grammatical rules may be seriously impacted, making any explicit grammar instruction even more demanding; (5) FLSP teachers' reliance on the students' greater cognitive maturity that should enable them to monitor their own output with a view to improving their interlanguage; and lastly, (6) some teachers' educational belief in the lesser pedagogical value of instructed FL teaching/learning (Klapper, 2006). In other words, FLSP teachers who prefer implicit over explicit instructional approach do not assume that the provision of explicit grammar instruction would enhance the students' interlanguage.

They also emphasize that they like the fact that implicit grammar instruction tends to take place naturally and automatically. Perceived from the students' perspective, teachers do not seem to make any conscious effort to explain the grammatical rules. However, a downside to this may be that the students commonly do not perceive the teacher's implicit feedback as corrections. Similarly, implicit grammar does not seem to make the students aware of their conscious effort to learn grammar, or, better, it leaves them unaware that their metalinguistic awareness is being raised. In the words of Šarolta (ESP; faculty with continuity), 'Implicit grammar instruction seems more appropriate for the tertiary level. However, if FL attrition is really advanced, then explicit grammar instruction is also necessary'. Nataša (ESP; faculty with continuity) thinks that 'focus on grammar is necessary, but... has to be tackled implicitly. Only grammar that is relevant to an FLSP has to be covered while any other grammatical problems should be tackled according to the target group's needs'.

\section{Discussion and Conclusion}

The outcomes of the study suggest that at the faculties without FL continuity at the secondary/tertiary interface the consequences of the prior incomplete FL acquisition from the pre-tertiary period combine with the FL discontinuity period and result in dire language consequences. Based on the interviews, two main reasons for maintaining FL continuity at the secondary/tertiary interface are the inseparable connection between general FL and subsequent FLSP instruction, and secondly, the disappearance of the logical structure of a general FL that impedes the building of FLSP knowledge in higher education settings. All interviewees from the study are already utilizing different methods to alleviate the ill-effects of FL discontinuity periods; however this is where the differences among them occur since they may decide to place the emphasis of FLSP instruction on (1) all FL abilities; (2) on selected FL abilities; (3) on FL lexis, and (4) on grammar.

The interviewees who emphasise FL abilities admit that the downside of this method of offsetting the consequences of FL discontinuity may be the fact that it is impossible for FLSP teachers to clearly define future work-oriented FL abilities for different job tasks of FLSP students. Since these are practically indefinable, more or less focus on any of various FL abilities in FLSP class is potentially less than profitable.

On the other hand, the interviewees who place emphasis on FL lexis acknowledge the fact that pre-experience second-year students still cannot bring any discipline-specific carrier content into the FLSP study process, making it quite difficult for FLSP teachers to develop FL abilities and specialized lexis at the start of FLSP classes.

Consequently, the results indicate that almost all FLSP teachers have come to realize that a combination of grammar and communicative activities may be optimum for effective FLSP learning (Fotos, 2005). As a means of bridging a gap opened in general FL by FL discontinuity, the informants appear to resort to grammar revision along with the right combination of implicit and explicit grammar instruction in otherwise communicative FLSP contexts.

Grammar is far from being perceived as paramount by any of the FLSP teachers but appears to be a logical choice to foster a natural transition from ailing general FL to FLSP instruction. According to the results, there is no overt explanation or deliberate discussion of grammatical forms, since FLSP teachers are aware that explicit grammar input rarely automatically transforms into productive communicative output. Explicit grammar explanations are only a means to an end and only for about one third of the informants. For the other two thirds at tertiary institutions without FL continuity the results confirm the use of implicit, incidental discussion of grammar - an approach to grammar that retains a strong communicative quality with a lesser interest in the 
structural and formal properties of an FL. While dealing with grammar the teachers are searching for the optimal balance between meaning and form, providing a lot of/enough controlled practice and, at the same time, keeping the students' engagement in situational meaning as primary and their attention to linguistic form secondary (Norris \& Ortega, 2000).

The problem of FL discontinuity at the secondary/tertiary interface carries broad social implications. The question of inefficient or non-existent FL skills has long been known as especially acute in the contemporary global business community (Ozolins, 2003; Clarke, 2000; Klapper, 2006; CILT, ELAN, 2006). FL discontinuity is topical within every FL professional teaching/learning community encountering the problem. Therefore the outcomes of the research are intended to assist all FLSP teachers at higher education institutions without FL continuity. Based on the study results, FLSP teachers will anticipate the effects of the attrition of general FL as a consequence of incomplete FL acquisition prior to the start of FLSP instruction. Consequently, they may realize that these seriously hinder any subsequent FLSP development. Furthermore, the results may encourage them to consider grammar in diverse FLSP contexts as a common denominator or a tangible remnant from the secondary school at hand for FLSP teachers and students that, if necessary, could provide a link for a natural transition between general FL and FLSP. The research therefore points towards grammar as an aid that could be used to help the students resume a continuation of interrupted FL learning, albeit more often best used implicitly.

Most importantly, the present research has contributed new data to the existing theoretical postulations of FL instruction, undoubtedly indicating the possibility of equalizing the differences between the two seemingly different instructional approaches: the informants, proponents and opponents of explicit/implicit grammar approaches appear to rely on the same prerequisite, if not with an identical goal in mind. The reliance seems to be on the fact that on entry FLSP students have reached the requisite cognitive developmental stage. Teachers as proponents of explicit grammar argue that this developmental stage should be utilized to accumulate the students' declarative metalinguistic knowledge. Conversely, the teachers as proponents of implicit grammar claim this stage is necessary to engage the students' perception of FL input with a view to enhancing their subsequent awareness of the discrepancy between the correct FL input and their incorrect interlanguage, without necessarily developing their declarative metalinguistic knowledge.

Further studies of the effects of FL discontinuity at the secondary/tertiary interface might consider the possibility of complementing qualitative with quantitative data, the lack of which is one of the limitations of the present study. Another hindrance that should be brought to the attention of any future studies is that the faculties/schools/colleges with FL discontinuity are geographically randomly dispersed in various countries in the EU. Logically, that makes conducting in-depth interviews rather difficult. A further problem is the rather feeble response rate in the present study, which should be taken into account in any further research involving FLSP teachers' participation in time-consuming interviews.

\section{References}

Bybee, J. (2008). Usage-based grammar and second language acquisition. In P. Robinson, \& N. C. Ellis (Eds.), Handbook of Cognitive Linguistics and Second Language Acquisition. New York: Routledge. pp. 216-33.

Celce-Murcia, M. (2001). Teaching English as a Second or Foreign language (Ed.). (3rd edition). Boston, Mass: Heinle \& Heinle.

CILT: The National Centre for Languages. (2006). ELAN: Effects on the European Union Economy of Shortages of Foreign Language Skills in Enterprise. Retrieved from http://ec.europa.eu/education/languages/Focus/docs/elan-sum_en.pdf (March 10, 2011)

Clarke, W. M. (2000). The use of foreign languages by Irish exporters. European Journal of Marketing, 34(1/2), 80-90. http://dx.doi.org/10.1108/03090560010306214

Cook, V. (2001). Second Language Learning and Language Teaching (3rd ed.). London, New York: OUP.

Crossling, G., \& Ward, I. (2002). Oral communication. English for Specific Purposes, 21, 41-57.

Cunningham, D. (2004). 20 years of transition without much change. Babel, 38(3), 16-24.

Cunningham, D. (2010). Continuity in Learning Languages. NZALT Biennial National Conference Christchurch New Zealand. Retrieved from http://www.fiplv.org/issues/continuityinlearning.pdf (October 25, 2011)

Čepon, S. (2006). An analysis of the Linguistic Needs of Business English Students at the Faculty of Economics, Ljubljana. Unpublished doctoral thesis. Ljubljana: University of Ljubljana, Faculty of Arts.

de Bot, K., \& Stoessel, S. (2000). In search of yesterday's words. Applied Linguistics, 21(3), 364-384. 
DeKeyser, R. M. (2001). Automaticity and automatization. In P. Robinson (Ed.), Cognition and Second Language Instruction. Cambridge: CUP. pp. 125-51.

DeKeyser. R. M. (2007). Study abroad as foreign language practice. In R. M. DeKeyser (Ed.), Practice in Second Language. New York: CUP. pp. 208-26.

Denzin, N. K., \& Lincoln, Y. S. (2000). Handbook of Qualitative Research. London. Sage Publications Ltd.

Djurić, M., Godnič Vičič, Š., \& Jurkovič, V. (2008). LSP in Slovenian higher education. In J. Skela (Ed.), Learning and Teaching foreign languages in Slovenia: a review of current theory and practice. Ljubljana: Tangram. pp. 523-542.

Djurić, M., \& Jurković, V. (2008). Foreign languages for specific purposes in Slovene higher education. In Languages in Education, Proceedings. Ljubljana. pp. 215-22.

Dörnyei, Z. (2009). The Psychology of Second Language Acquisition. Oxford: OUP.

Doughty, C. (2001). Cognitive underpinings of focus on form. In P. Robinson, Cognition and Second Language Instruction. Cambridge: CUP. pp. 206-57

Doughty, C. J. (2003). Instructed SLA: Constraints, Compensation, and Enhancement. In C. J. Doughty, \& M. H. Long (Eds.), The Handbook of Second Language Acquisition. Oxford: Blackwell. pp. 256-310.

Ecke, P. (2004). Language Attrition and Theories of Forgetting. International Journal of Bilingualism, 8(3), 321-354. http://dx. doi.org/!0.1177/13670069040080030901

ECML. The European Centre for Modern Language. Retrieved from http://www.ecm,.at/Actavities/Continuhtyinlanguagelearning/tabid/146/language/en-GB/Default.aspx (May 10, 2011)

Ellis, N. C. (2005). At the interface: Dynamic IntEractions of explicit and implicit knowledge. SSLA, 27, 305-352. http://dx. doi.org/10.1017/S027226310505014X

Ellis, R. (2005). Measuring implicit and explicit knowledge of a second language. SSLA, 27, 141-172. http://dx.doi.org/10.1017/S0272263105050096

Ellis, R. (2006). Current issues in the Teaching of Grammar. TESOL Quarterly, 40(1), 83-107.

Evans, S. (2010). Business as usual: The use of English in the professional world in Hong Kong. English for Specific Purposes, 29, 153-167. http://dx. doi.org/10.1016/j.esp.2009.11.005

Fotos, S. (2001).Cognitive Approaches to Grammar Instruction. In M. Celce-Murcia (Ed.), Teaching English as a Second or Foreign language. Boston, Mass.: Heinle \& Heinle. pp. 267-83.

Hafizoah, K., \& Fatimah, A. (2010). English communicative events and skills at the workplace. English for Specific Purposes, 29, 169-182.

Hansen, L., \& Reetz - Kurashige, A. (1999). Investigating Second Language Attrition. In L. Hansen (Ed.), Second Language Attrition in Japanese Contexts. New York: OUP. pp. 3-18.

Hansen, L. (2001). Language attrition. Annual Review of Applied Linguistics, 21, 60-73. http://dx.doi.org/10.1017/S0267190501000046

Hayland, K. (2002). Specificity revisited: how far should we go now? English for Specific Purposes, 21, 385-395.

Hulstijn, J. H. (2001). Intentional and incidental second language vocabulary learning: a reappraisal of elaboration, rehearsal and automaticity. In P. Robinson (2001), Cognition and Second Language Instruction. Cambridge: CUP.

Jurkovič, V., Djurić, M., \& Godnič Vičič, Š. (2008). Status of LSP Teachers in Higher Education. In M. Brkan, Š. Godnič Vičič, M. Jarc, V. Jurkovič, V., \& V. Zorko (Eds.), LSP and the role of LSP teachers in Slovenian education area. Inter Alia (1). Ljubljana: SDUTSJ. pp. 45-69.

Klapper, J. (2006). Understanding and developing good practice. London: CILT.

Larsen-Freeman, D. (2001). Teaching Grammar. In M. Celce-Murcia (Ed.), Teaching English as a Second or Foreign language. Boston, Mass.: Heinle \& Heinle. pp. 251-66.

Lightbown, P. M., \& Spada, N. (2006). How Languages Are Learnt. Oxford: OUP.

Lyster, R. (2004a). Research on form-focused instruction in immersion classrooms. French Language Studies, (14), 321-341. 
Lyster, R. (2004b). Differential effects of prompts and recasts in form-focused instruction. SSLA, 26, 399-432. http://dx. doi.org/10.1017/S0272263104263021

Nassaji, H. (2000). Towards Integrating Form-Focused Instruction and Communicative Interaction in the Second Language Classroom. The Modern Language Journal, 84(ii), 241-250.

Norris, J. M., \& Ortega, L. (2000). Effectiveness of L2 instruction. Language Learning, 50(3), 417-528.

Ozolins, U. (2003). Language and Economics: Mutual incompatibilities, or a Necessary Partnership. Current Issues in Language Planning, 4(1), 67-83.

Pienemann, M. (2003). Language Processing Capacity. In C. J. Doughty, \& M. H. Long (Eds.), The Handbook of Second Language Acquisition. Oxford: Blackwell. pp. 679-714.

Purvis, K., \& Ranaldo, T. (2003). Providing Continuity in Language Teaching and Learning from primary to secondary. Babel, 38(1), 13-18.

Rižnar, I. (2010). Hrabri novi svet: konferenca Izzivi jezika stroke v 21. stoletju. Management, 5(1), 89-92.

Robinson, P. (2003). Attention and memory during SLA. In C. J. Doughty, \& M. H. Long (Eds.), The Handbook of Second Language Acquisition. Oxford: Blackwell. pp. 631-678.

Räisänen, C., \& Fortanet-Gomez, I. (2008a). The State of ESP teaching and learning in Western European higher education after Bologna. In I. Fortanet-Gomez, \& C. Räisänen, C. (Eds.), ESP in European Higher Education. Amsterdam \& Philadelphia: John Benjamins. pp. 11-51.

Scarino, A. (2003). Transition and Continuity in Learning languages in School Setting. Babel, 38(1), 4-7.

Schmid, M. S., \& de Bot, K. (2006). Language attrition. In A. Davies, \& C. Elder (Eds.), The handbook of Applied Linguistics. Oxford: Blackwell Publishing Ltd. pp. 210-34.

Schmitt, E. (2010). When boundaries are crossed: Evaluating language attrition data from two perspectives. Bilingualism: Language and Cognition, 13(1), 63-72.

Segalowitz, N. (2003). Automaticity and Second Languages. In C. J. Doughty, \& M. H. Long (Eds.), The Handbook of Second Language Acquisition. Oxford: Blackwell. pp. 382-408.

Skela, J., Sešek, U., \& Dagarin Fojkar, M. (2009). Literacy in a second/foreign language for young learners. In K. Pižorn (Ed.), Learning and teaching additional languages in childhood. Ljubljana: Zavod RS za šolstvo. pp. $220-45$.

Skela, J. (2011). The treatment of Communicative competence in the "Common European Framework of Reference for Languages". Sodobna pedagogika, (2), 114-133.

Steigler-Peters, S., Moran, W., Piccioli, M. T., \& Chesterton, P. (2003). Addressing Transition Issues in Languages. Education, 38(1), 31-38.

Tudor, I. (1996). Learner-centredness as Language Education. Cambridge: CUP.

Turula, A. (2002). Language Anxiety \& Classroom Dynamics: A Study of Adult Learners. English Teaching Forum, 40(2), 28-33.

Zavašnik, M., \& K. Pižorn. (2006). Povratni učinek nacionalnih tujejezikovnih preizkusov: opredelitev pojma in posnetek stanja v svetu. Sodobna pedagogika, 57(1), 76-89.

Yoshitomi, A. (1992). Towards a model of language attrition. Issues in Applied Linguistics, 3(2), 293-318.

\section{Notes}

Note 1.

The term FL for Specific Purposes/FLSP is used as it is analogous with the term English for Specific Purposes/ESP. Just like the latter, FLSP is an umbrella term that includes FL for academic purposes and FL for occupational purposes as two main sub-divisions. The former further encompasses FL for science/technology and FL for medical and legal purposes, whereas the latter refers to FL for professional purposes (which includes FL for business purposes) and FL for vocational purposes.

Note 2 .

An example of recasting: Student: Yes, I buyed it.

Teacher: So, you bought it?

Student: Yes, I bought it. 